\title{
Nanostructured Nickel on Porous Carbon-Silica Matrix as an Efficient Electrocatalytic Material for a Non-Enzymatic Glucose Sensor
}

\author{
Nassim Zahmouli ${ }^{1,2}$, Silvia Marini ${ }^{1}\left({ }^{10}\right.$, Mouna Guediri $^{2}$, Nabil Ben Mansour ${ }^{2}$, Mokhtar Hjiri ${ }^{3}$,

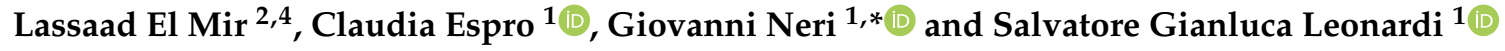 \\ 1 Department of Engineering, University of Messina, 98166 Messina, Italy; \\ nassim.zahmouli1989@gmail.com (N.Z.); smarini@unime.it (S.M.); espro@unime.it (C.E.) \\ leonardis@unime.it (S.G.L.) \\ 2 Laboratory of Physics of Materials and Nanomaterials Applied at Environment, Faculty of Sciences of Gabes, \\ Gabes 6072, Tunisia; mouna.guediri91@gmail.com (M.G.); benmansour.nabil@yahoo.fr (N.B.M.); \\ lassaad.elmir@fsg.rnu.tn (L.E.M.) \\ 3 Physics Department, Faculty of Sciences, King Abdulaziz University, Jeddah 21589, Saudi Arabia; \\ m.hjiri@yahoo.fr \\ 4 Department of Physics, Al Imam Mohammad Ibn Saud Islamic University, Riyadh 11623, Saudi Arabia \\ * Correspondence: gneri@unime.it; Tel.: +39-090-397-7297
}

Received: 24 September 2018; Accepted: 9 November 2018; Published: 16 November 2018

\begin{abstract}
Nanostructured nickel on porous carbon-silica matrix (N-CS) has been synthesized using a sol gel process and subsequent pyrolysis treatment at a temperature of $650^{\circ} \mathrm{C}$. The morphology and microstructure of the N-CS sample has been investigated using XRD (X-ray Diffraction), SEM-EDS (Scanning Electron Microscopy-Energy Dispersive X-ray Spectroscopy), and BET (Brunauer-Emmett-Teller) analysis. The synthesized nanocomposite has been used for developing NCS-modified screen-printed electrodes (NCS-SPCEs) and was applied in the electrochemical monitoring of glucose. After electrochemical activation, via cycling the modified electrode in a potential window from 0 to $0.8 \mathrm{~V}$ in $0.1 \mathrm{M} \mathrm{KOH}$ solution, the fabricated NCS-SPCEs electrodes were evaluated for the voltammetric and amperometric determination of glucose. The developed sensors showed good sensing performance towards glucose, displaying a sensitivity of $585 \mu \mathrm{A} / \mathrm{mM} \mathrm{cm}^{-1}$ in the linear range from 0.05 to $1.5 \mathrm{mM}$, a detection limit lower than $30 \mu \mathrm{M}$ with excellent selectivity.
\end{abstract}

Keywords: non-enzymatic glucose sensor; electrochemical sensor; porous carbon nanocomposite; carbon-silica-nickel

\section{Introduction}

In recent years, materials, processes, and technologies at the nanoscale level have opened new possibilities for the development of novel electrochemical sensors. For example, nanoscale sized materials have been extensively proposed to promote electrocatalytic reactions that are involved in the electrochemical sensing of numerous analytes of practical interests over modified electrodes. Among these analytes, glucose quantification assumes a great importance for clinical diagnosis, food analysis, personal care, and control of industrial bioprocesses [1-11]. Enzyme-based electrochemical glucose sensors are very good at meeting the requirements of good selectivity and sensitivity required by these applications, but the drawbacks arising from their thermal/chemical instabilities and the complex fabrication procedures limit their further progress [4-6]. These drawbacks have stimulated intensive research efforts aimed at the development of non-enzymatic electrochemical glucose sensors [7-11]. 
The sensing mechanism of non-enzymatic glucose sensors is based on the direct oxidation of glucose, where the key factor is the electrocatalytic activity of the electrode material, which affects their sensitivity and the selectivity [12]. Among several electrocatalysts so far proposed, Ni-based materials still remain the most promising candidates. The electrocatalytic effect of Ni-based sensors generally relies on the $\mathrm{Ni}^{2+} / \mathrm{Ni}^{3+}$ redox couple that result from the $\mathrm{Ni}(\mathrm{OH})_{2} / \mathrm{NiOOH}$ system formed on the working electrode surface in alkaline media $[13,14]$. Compared to bulk material, nanostructured forms of Ni-based materials, such as Ni nanowire arrays [15], NiO hollow microspheres [16], $\mathrm{Ni}(\mathrm{OH})_{2}$ nanoplates [17], and Ni nanoparticles [18] are proven to allow the development of high sensitivity glucose sensors.

To enhance the dispersion of $\mathrm{Ni}$ nanoparticles and ensure longer stability, Ni nanoparticles are generally dispersed on suitable substrates. As a proof of the effectiveness of this procedure, a variety of Ni nanoparticles dispersed onto metal oxides or conductive carbon matrix, such as graphene and carbon nanotubes, recently received great attention for glucose sensing [19-23]. Porous carbon has also attracted extensive research interest because of its stable chemical properties, high electrical conductivity, and low cost [24,25]. In addition, the simple large scale synthesis of porous carbon has favored its wide use as an electrode material in analytical applications [26]. Therefore, the simple synthesis of suitable metal oxide electrocatalysts directly incorporated into porous carbons open new opportunities for the practical developing of electrochemical sensors.

In previous research work we reported the electrocatalytic characteristics of novel composite material based on Ni nanoparticles incorporated in a porous carbon matrix. The influence of Ni loading into the carbon matrix has been investigated. The sensor based on $30 \mathrm{wt} \% \mathrm{Ni}$ loaded carbon showed the best electrochemical performance towards glucose oxidation in alkaline media. The improved electrocatalytic behavior was ascribed to a compromise between the quantity and dispersion of nickel particles in the carbon matrix [27].

In order to favor further the dispersion of the catalyst phase, thus helping in reducing further its load, carbon-silica (CS) matrix has been used as a support. Metal catalysts supported on CS have shown superior catalytic activity and stability compared to metal catalysts/carbon systems [28,29]. The CS support joint the advantages of both the organic carbon constituent, such as flexibility and versatility for further functionalization, and of the inorganic silica component, such as hydrophilicity, good thermal and mechanical properties, and high stability. Here, the excellent electrochemical performance towards glucose oxidation in alkaline media of nickel incorporated in a porous carbon-silica matrix $(\mathrm{N}-\mathrm{CS})$ have been reported and discussed.

\section{Experimental}

\subsection{Synthesis of the Porous Carbon Composite}

First, the pure $\mathrm{NiO}$ and $\mathrm{SiO}_{2}$ nanoparticles were prepared using the sol-gel process. $\mathrm{NiO}$ nanoparticles were synthesized by using the nickel(II) chloride $\left(\mathrm{NiCl}_{2} \cdot 6 \mathrm{H}_{2} \mathrm{O}\right)$ precursor dissolved in methanol. After $15 \mathrm{~min}$ of magnetic stirring at room temperature, the solution was placed in an autoclave and dried in a supercritical condition of ethyl alcohol $\left(\mathrm{Tc}=250^{\circ} \mathrm{C}, \mathrm{Pc}=7 \mathrm{MPa}\right)$ to extract the solvent. The obtained aerogel was annealed at $500{ }^{\circ} \mathrm{C}$ in air for $2 \mathrm{~h}$. The same protocol was used to synthetize the $\mathrm{SiO}_{2}$ using a sol-gel process using the (tetra-ethyl-ortho-silicate) $\mathrm{Si}\left(\mathrm{C}_{2} \mathrm{H}_{5} \mathrm{O}\right)_{4}$ precursor in methanol and mixed by magnetic stirring at room temperature for $15 \mathrm{~min}$. Then, the obtained solution was placed in an autoclave and dried in a supercritical condition of ethyl alcohol $\left(\mathrm{Tc}=250{ }^{\circ} \mathrm{C}\right.$, $\mathrm{Pc}=7 \mathrm{MPa})$.

The synthesis of the N-CS composite was accomplished in three steps. In the first one, organic wet gel was prepared by mixing $15 \mathrm{~mL}$ formaldehyde $(\mathrm{F})$ with dissolved $6.3 \mathrm{~g}$ pyrogallol $(\mathrm{P})$ in a $30 \mathrm{~mL}$ water (W) solution, using $0.022 \mathrm{~g}$ picric acid (PA) as a catalyst and $0.5 \mathrm{~g} \mathrm{NiO}$ and $10 \mathrm{~g} \mathrm{SiO}_{2}$ as incorporated elements with a weight ratio of $\mathrm{Ni} / \mathrm{C}$ of 0.01 and $\mathrm{Si} / \mathrm{C}$ of 0.2 . In the second step, the obtained wet gel was dried in humid atmosphere at $50{ }^{\circ} \mathrm{C}$ for 2 weeks. To obtain a structured 
xerogel, the sample was transferred to an incubator and dried at $150{ }^{\circ} \mathrm{C}$ at a heating rate of $10{ }^{\circ} \mathrm{C} /$ day. The drying temperature was then maintained for two days. The sample was then heated up to $650{ }^{\circ} \mathrm{C}$ in nitrogen, with a heating rate of $5^{\circ} \mathrm{C} / \mathrm{min}$, and this temperature was finally maintained for $2 \mathrm{~h}$. After that, the samples were cooled naturally.

For the preparation of the modified sensor, $5 \mathrm{mg}$ of $\mathrm{N}-\mathrm{CS}$ composite was dispersed in $1 \mathrm{~mL}$ of double-distilled water then sonicated until homogenous black suspensions were obtained. The commercial screen-printed carbon electrodes (SPCEs), purchased from DropSens, Llanera (Asturias) Spain, consists of a planar substrate equipped with a $4 \mathrm{~mm}$ in diameter $\left(0.125 \mathrm{~cm}^{2}\right) \mathrm{carbon}^{2}$ working electrode, a carbon counter electrode, and a silver pseudo-reference electrode. The working electrode was modified using a wet impregnation method, casting different amounts $(2.5-20 \mu \mathrm{L})$ of above suspension on its surface, then allowed to dry at room temperature.

\subsection{Characterization and Electrochemical Tests}

The crystalline structure of synthesized materials was investigated using X-ray powder diffraction (XRD) by means of a Bruker D8 Advance A 25 X-ray diffractometer operating at $40 \mathrm{kV}$ and in the range $10-80^{\circ}(2 \theta)$, with an increasing rate of $0.01^{\circ} / \mathrm{s}$. The morphology of N-CS fresh and used samples was observed using FEI Quanta 450 instrument. BET surface area and porosity of the samples were evaluated by nitrogen adsorption and desorption isotherms carried out at $77 \mathrm{~K}$ by a Quantachrome ${ }^{\circledR}$ ASiQwin ${ }^{\mathrm{TM}}$ instrument (Anton Paar Companies, Graz, Austria).

Electrochemical experiments were performed with a DropSens $\mu$ Stat 400 potentiostat/galvanostat. The electrochemical behavior of different prepared sensors was investigated by cyclic voltammetry $(\mathrm{CV})$ in a $0.1 \mathrm{M} \mathrm{KOH}$ solution in the range of potential $0-0.8 \mathrm{~V}$, in the presence and absence of glucose and at a scan rate of $50 \mathrm{mVs}^{-1}$. The sensing performances of the developed sensor was investigated via chronoamperometric measurements in $0.1 \mathrm{MKOH}$, recording the current at a fixed optimal potential during successive additions of glucose.

\section{Results and Discussion}

\subsection{Characterization of the N-CS Composite}

The structure and morphology of the as-prepared N-CS composite powder and after electrochemical activation on SPCE were investigated using XRD, SEM and EDS analysis. Figure 1 a shows the XRD spectra of the N-CS powder where three distinct reflection peaks at $44^{\circ}, 51^{\circ}$, and $76^{\circ}$, matching with the (111), (200), (220) planes of metallic nickel (JCPDS 04-0850), can be observed. Metallic Ni comes from the reduction of $\mathrm{NiO}$ nanoparticles during the pyrolysis treatment in inert atmosphere [27]. The crystallite size of metallic nickel, calculated using Sherrer's equation from the full width at half maximum intensity (FWHM) measured on the (111) diffraction peak, was about $32 \mathrm{~nm}$. The broad peak centered at about $22^{\circ}$ can be ascribed to the combination of both amorphous carbon and $\mathrm{SiO}_{2}$ phases [30]. Unlike nickel, the absence of metallic silicon diffraction peaks suggests that the pyrolysis treatment did not lead to reduction of $\mathrm{SiO}_{2}$.

BET surface area and porosity of the samples were evaluated using nitrogen adsorption and desorption isotherms carried out at $77 \mathrm{~K}$. Through the BJH (Barret-Joyner-Halenda) method, the high surface area $\left(\mathrm{SA}=163 \mathrm{~m}^{2} / \mathrm{g}\right)$, pore volume of $1.55 \mathrm{cc} / \mathrm{g}$, and pore diameter of $1.425 \mathrm{~nm}$, of the as prepared nanocomposite N-CS sample was revealed.

Figure $1 \mathrm{~b}$ shows the morphology of the as-prepared N-CS composite, where the uniform porous structure was observed to cover the bare electrode surface (see inset). Using EDS analysis (Figure 1c), the composition of the material was: $26.82 \mathrm{wt} \% \mathrm{C}, 25.36 \mathrm{wt} \% \mathrm{Si}, 1.1 \mathrm{wt} \% \mathrm{Ni}$, and $46.72 \mathrm{wt} \% \mathrm{O}$. Figure $1 \mathrm{~d}$ shows the morphology of the N-CS composite modified SPCE after the electrochemical activation as discussed below. As observed, the N-CS composite film showed a more rough and porous surface, likely due to the growth of nickel oxy-hydroxide structures. 

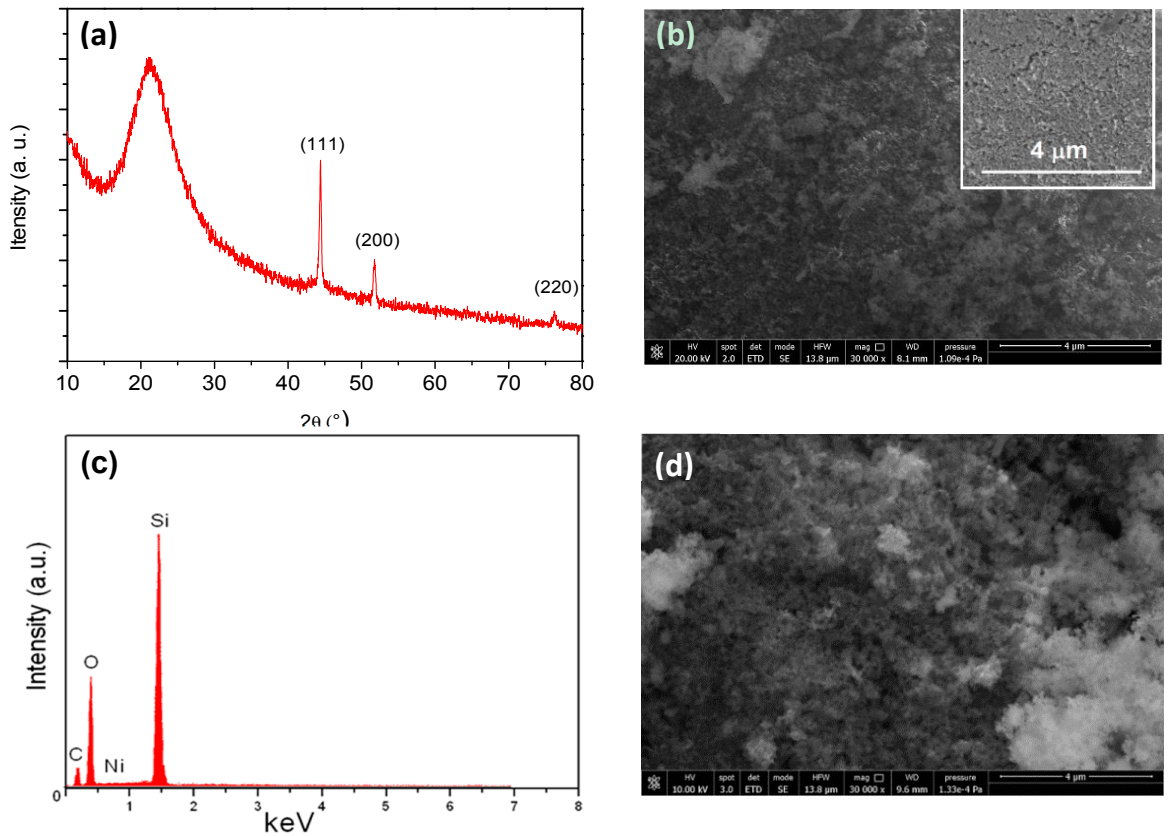

Figure 1. (a) XRD spectra, (b) SEM image of as-prepared N-CS powder, (c) EDS spectra, and (d) SEM image of the N-CS composite modified SPCE after the electrochemical activation. Inset in Figure $1 b$ shows the surface of bare SPCE.

\subsection{Cyclic Voltammetry Activation of Ni Nanoparticles}

Electrochemical behavior of the modified SPC electrode with N-CS was investigated using CV. First, the electrode was cycled in a $0.1 \mathrm{M} \mathrm{KOH}$ solution in the potential window $0-0.8 \mathrm{~V}$ at $50 \mathrm{mVs}^{-1}$, until a stable signal was obtained (Figure 2). During the first cycle, only a strong increase of the anodic current with onset potential at about $0.5 \mathrm{~V}$, which can be attributed to the oxygen evolution reaction, was noted. During the first ten cycles, it was observed that the appearance of an oxidation peak, which after the 10th cycle, remained located around $0.55-0.6 \mathrm{~V}$. A broad reduction peak, initially at $0.5 \mathrm{~V}$ and moving towards more negative potentials while increasing in intensity as the number of cycles increased, was also seen to compose a redox couple. The position, separation, and shape of these oxidation and reduction peaks, which are ascribed to the growth of different nickel oxide-hydroxide species, have been demonstrated to be related to the experimental conditions during the electrochemical treatment [31].

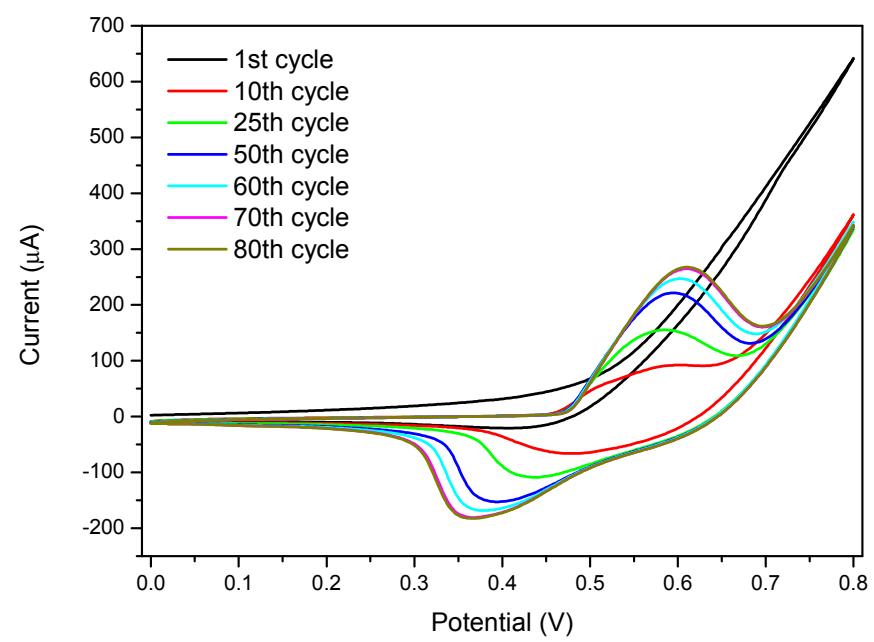

Figure 2. Evolution of the CV curves with number of cycles of N-CS modified SPCE in $0.1 \mathrm{M} \mathrm{KOH}$ at a scan rate of $50 \mathrm{mVs}^{-1}$. 
Furthermore, the current of the redox peaks increased cycle by cycle reaching an equilibrium after about 60-70 cycles without showing noticeable modification of the shape of the voltammogram with further cycles. A similar result was observed in previous works, showing that continuous dynamic cycling of a nickel-based electrode in alkaline solutions induced the growth of hydrous oxide species on nickel surface [31-33]. In order to understand the evolution of the electrode during voltammetric cycling in an alkaline solution, it is necessary to refer to the possible reaction occurring for nickel. The starting condition for nickel in a N-CS composite after pyrolysis treatment can be: (i) the metallic phase $\mathrm{Ni}(0)$ due to the thermal reduction in absence of oxygen as confirmed by XRD, or (ii) nickel hydroxide $\mathrm{Ni}(\mathrm{OH})_{2}$ as an effect of oxidation of $\mathrm{Ni}(0)$ by atmospheric exposure. Furthermore, when the electrode was dipped in the $0.1 \mathrm{M} \mathrm{KOH}$ solution, a Ni hydroxide layer was instantaneously formed on the surface of the Ni particles according to Equation (1). This was because, in strong alkaline solution, the $\mathrm{Ni}(\mathrm{OH})_{2}$ phase was stable at potentials more positive than $-0.4 \mathrm{~V}$ [34].

$$
\begin{gathered}
\mathrm{Ni}+2 \mathrm{OH}^{-} \rightleftharpoons \mathrm{Ni}(\mathrm{OH})_{2}+2 \mathrm{e}^{-} \\
\mathrm{Ni}(\mathrm{OH})_{2}+\mathrm{OH}^{-} \rightleftharpoons \mathrm{NiOOH}+\mathrm{H}_{2} \mathrm{O}+\mathrm{e}^{-}
\end{gathered}
$$

During the successive cycles, the $\mathrm{Ni}(\mathrm{OH})_{2}$ phase was further oxidized to oxy-hydroxides $\mathrm{NiOOH}$ species according to Equation (2). The achievement of an equilibrium after a certain number of cycles suggested that the formation of this new oxy-hydroxide species involved the entire bulk of the nickel particles. Observing the CV cycle after its complete stabilization, the cathodic peak appears to be constituted by the convolution of two reduction peaks. This could be due to the reduction of two different species $\gamma-\mathrm{NiOOH}$ and $\beta-\mathrm{NiOOH}$, respectively [35], which could be formed by direct oxidation of the $\alpha-\mathrm{Ni}(\mathrm{OH})_{2}$ phase or the $\beta-\mathrm{Ni}(\mathrm{OH})_{2}$ phase deriving from the first one in agreement to the Bode scheme [36] as described by Equations (3) and (4) below:

$$
\begin{array}{rlc}
\alpha-\mathrm{Ni}(\mathrm{OH})_{2}+\mathrm{OH}^{-} & \rightleftharpoons & \gamma-\mathrm{NiOOH}+\mathrm{H}_{2} \mathrm{O}+\mathrm{e}^{-} \\
\downarrow & & \beta-\mathrm{NiOOH}+\mathrm{H}_{2} \mathrm{O}+\mathrm{e}^{-}
\end{array}
$$

\subsection{Electrochemical Oxidation of Glucose on N-CS/SPCE}

Electrochemical activity of glucose at bare SPCE and a modified electrode was investigated using cyclic voltammetry (Figure 3). Bare SPCE did not show any redox peak in the absence or presence of $1 \mathrm{mM}$ glucose in a $0.1 \mathrm{M} \mathrm{KOH}$ solution (dot lines in Figure 3a). Modified N-CS/SPCE, after its activation, showed a large electrochemical activity also in a blank $0.1 \mathrm{M} \mathrm{KOH}$ solution according to the redox behavior of nickel phase as above discussed. In the presence of $1 \mathrm{mM}$ of glucose in a $0.1 \mathrm{M} \mathrm{KOH}$ solution, the anodic peak was higher than in its absence while the reduction was decreased (solid lines Figure 3a). The most accepted mechanism $[13,14,37]$ suggests that the increase of the anodic peak is due to the oxidation of glucose mediated by the $\mathrm{NiOOH}$ species, which are then consumed by the electrochemical oxidation of glucose to glucolactone according to Equation (5):

$$
\mathrm{NiOOH}+\text { glucose } \rightleftharpoons \mathrm{Ni}(\mathrm{OH})_{2}+\text { glucolactone }+\mathrm{e}^{-}
$$

With the aim to develop an electrochemical sensor for glucose monitoring, the modification of the electrode was optimized. In Figure $3 \mathrm{~b}$ are reported the anodic peak currents recorded in the presence of $1 \mathrm{mM}$ glucose, subtracted off the related background peak current in blank $0.1 \mathrm{M} \mathrm{KOH}$, for different modified electrodes prepared by casting different amount of N-CS composite on their surface. The error bars were calculated on three different series of prepared electrodes. By increasing the volume of the N-CS suspension casted on the working electrode surface, the response to glucose monotonically increased up to $20 \mu \mathrm{L}$. The further increase in the quantity of active material deposited 
on the electrode led to a poor reproducibility of the sensor response. This could be due to the formation of a mechanically unstable thick film, with successive leached from the electrode surface when immersed in solution. Therefore, the electrode modified with $20 \mu \mathrm{L}$ of active material suspension was used for the subsequent tests.
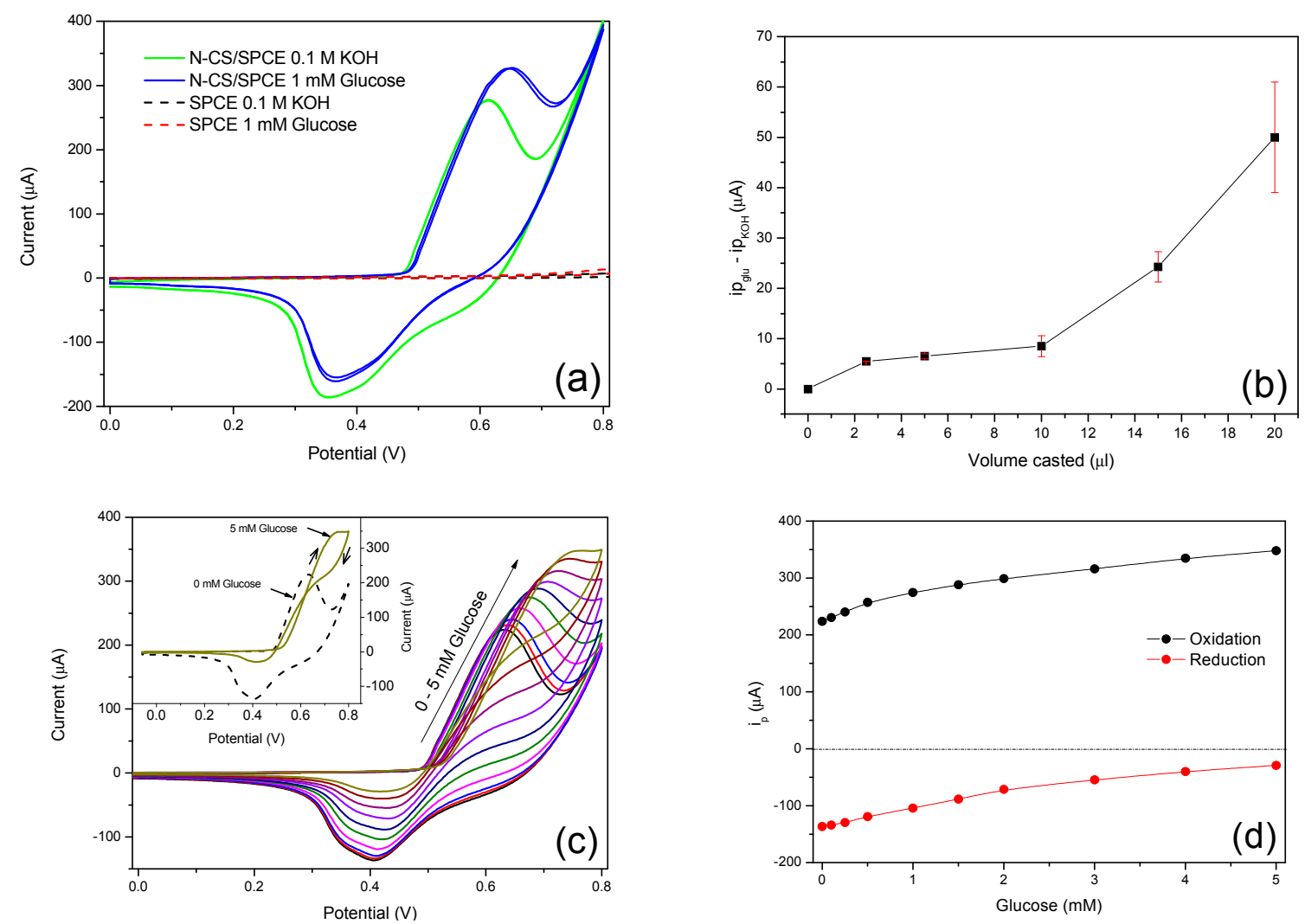

Figure 3. (a) CVs of bare SPCE and N-CS-modified SPCE in the absence and presence of $1 \mathrm{mM}$ glucose in $0.1 \mathrm{M} \mathrm{KOH}$ at a scan rate of $50 \mathrm{mVs}^{-1}$. (b) Response to $1 \mathrm{mM}$ glucose of N-CS modified SPCE as a function of different amounts of active material casted on a working electrode surface. (c) CVs of $20 \mu \mathrm{L}$ N-CS modified SPCE for different concentration of glucose $(0-5 \mathrm{mM})$ in $0.1 \mathrm{M} \mathrm{KOH}$ at a scan rate of $50 \mathrm{mVs}^{-1}$; inset: highlighting of $\mathrm{CV}$ curves in the absence and presence of $5 \mathrm{mM}$ glucose. (d) Behavior of anodic and cathodic peak currents as a function of glucose concentration.

Figure 3c,d shows CV curves recorded for different concentration of glucose between 0 to $5 \mathrm{mM}$ and the related calibration curves for oxidation and reduction peaks, respectively. During a forward scan from 0 to $0.8 \mathrm{~V}$, the anodic peak current increased while it slightly shifted to a higher potential with the glucose concentration. The reason for the peak potential shift has been ascribed to a prolonged oxidation cycle and/or a gradual change in local $\mathrm{pH}$ of the electrode surface [38]. A further anodic peak was also observed during the reverse sweep of the potential, suggesting that the catalytic oxidation of glucose was also evident on the cathodic scan.

This process, well observable in the presence of high concentration of glucose, as highlighted in the inset of Figure 3c, could be due to further glucose oxidation on the regenerated $\mathrm{NiOOH}$ sites after the first glucose oxidation process [39]. On the other hand, the cathodic peak decreased with an increase of glucose concentration as an effect of the consumption of $\mathrm{NiOOH}$ species induced by the oxidation of glucose [16].

In order to explore the mass transfer phenomenon for N-CS modified SPCE, CV was performed at different scan rates $(v)$ ranging from 10 to $100 \mathrm{mVs}^{-1}$ in blank $0.1 \mathrm{M} \mathrm{KOH}$ and in the presence of $1 \mathrm{mM}$ glucose. As shown in Figure $4 \mathrm{a}, \mathrm{b}$ and in the related insets, both oxidation and reduction peaks increased linearly with the square root of the scan rate. These observations revealed that $\mathrm{NiOOH}$ 
formation and its reduction steps, as well as the oxidation of glucose, were diffusion-controlled processes [40]. This means that the adsorption and reaction steps of the electroactive species were faster than their diffusion to, or away from, the electrode surface.
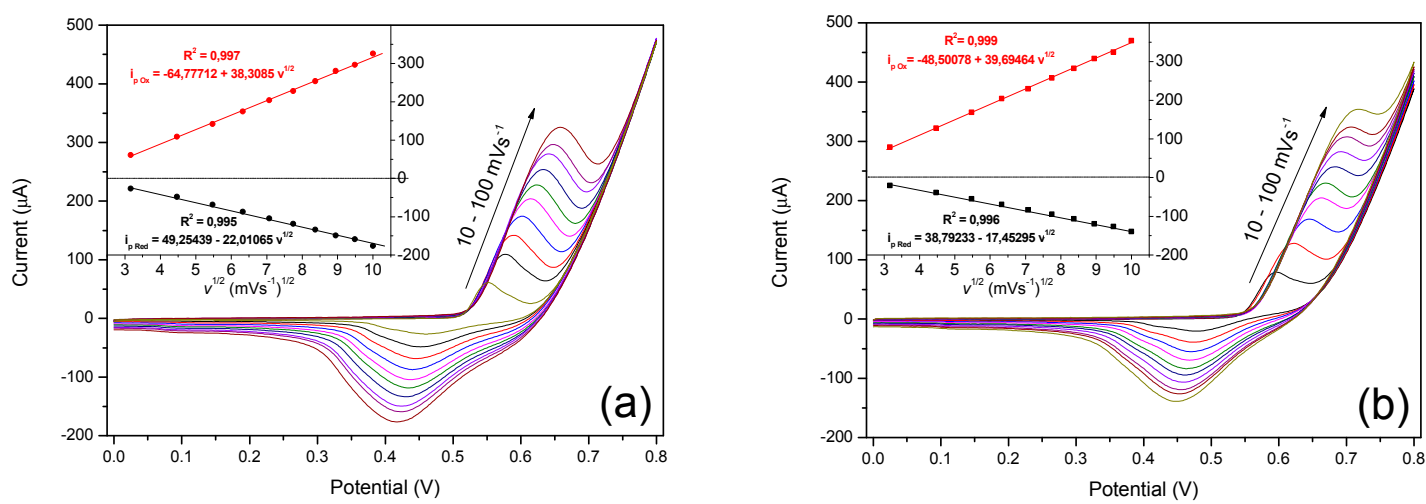

Figure 4. CVs of $20 \mu \mathrm{L} \mathrm{N}$-CS modified SPCE in the absence (a) and presence of $1 \mathrm{mM}$ glucose (b) in $0.1 \mathrm{M} \mathrm{KOH}$ at different scan rates between 10 and $100 \mathrm{mVs}^{-1}$; insets: plots of oxidation and reduction peak currents vs square root of scan rate $\left(v^{1 / 2}\right)$.

\subsection{Amperometric Response of the N-CS/SPCE Towards Glucose}

To optimize the amperometric response of N-CS/SPCE to glucose, chronoamperometric experiments were carried out at different applied potentials around the oxidation peak position as observed by $\mathrm{CV}$ analysis. Figure $5 \mathrm{a}$,b shows the amperometric responses of the electrode to four successive injections of $0.5 \mathrm{mM}$ glucose at various applied potentials from 0.5 to $0.7 \mathrm{~V}$ and the related calibration curves. At an applied potential of $0.5 \mathrm{~V}$, the sensor was almost insensitive, showing a very poor response during the additions of glucose. At higher applied potentials the sensors showed enhanced amperometic responses with the highest sensitivity at the potential of $0.6 \mathrm{~V}$. Further increase of the applied potential led to a decrease of the sensitivity until it was again almost insensitive to glucose at $0.7 \mathrm{~V}$. This can be due to the interfering effect of electroactive species coming from water splitting and/or by-products generated by glucose oxidation. Therefore, the applied potential of $0.6 \mathrm{~V}$ was selected as the optimum applied potential for the subsequent experiments.
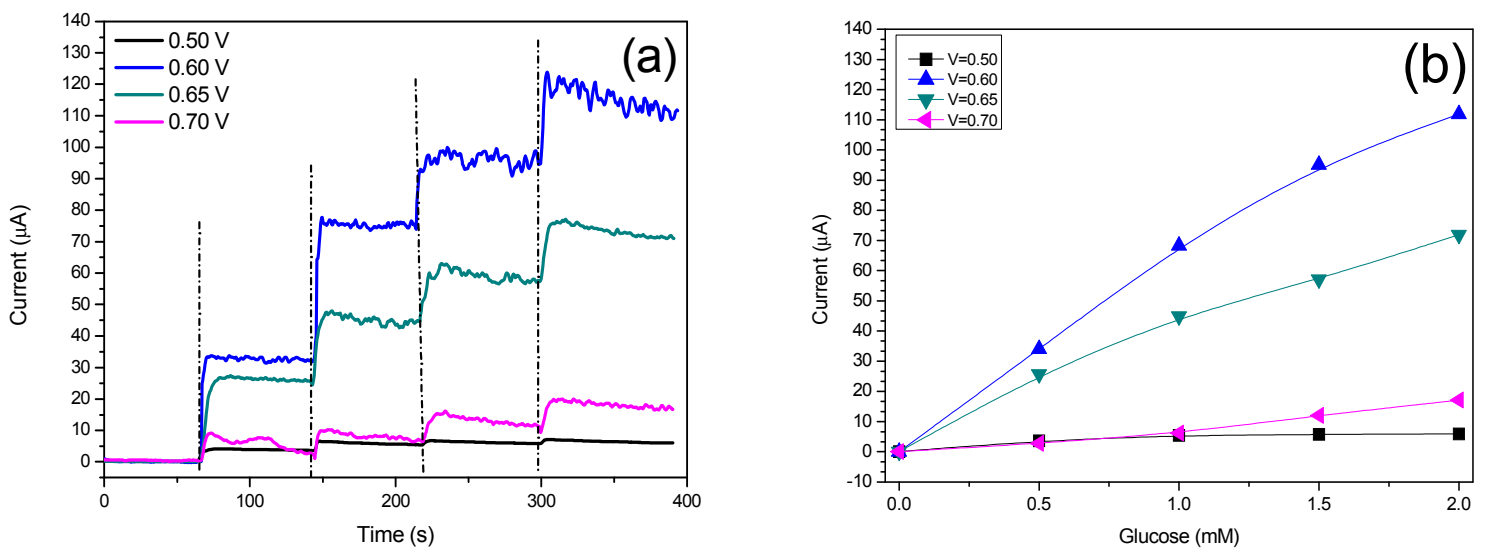

Figure 5. (a) Chronoamperometry of $20 \mu \mathrm{L} \mathrm{N-CS/SPCE} \mathrm{in} 0.1 \mathrm{M} \mathrm{KOH}$ after successive additions of $0.5 \mathrm{mM}$ glucose at different applied potentials and (b) corresponding calibration curves.

Figure 6 shows the chronoamperometric response recorded at the optimum potential of $0.6 \mathrm{~V}$ for successive additions of glucose from 0.05 to $5 \mathrm{mM}$. There is a linear relation between the current responses and glucose concentration in the range of $0.05 \mathrm{mM}$ to $1.5 \mathrm{mM}$ with a sensitivity of $584 \mu \mathrm{A} \cdot \mathrm{mM}^{-1} \cdot \mathrm{cm}^{-2}$, while saturation occurred for concentrations higher than $3 \mathrm{mM}$. The limit of 
detection of the sensor was calculated to be $0.03 \mathrm{mM}$ using a calibration curve and considering the formula $3 S_{y} / m$, where $S_{y}$ is the standard error of the $y$-intercept and $m$ is the slope of calibration curve.

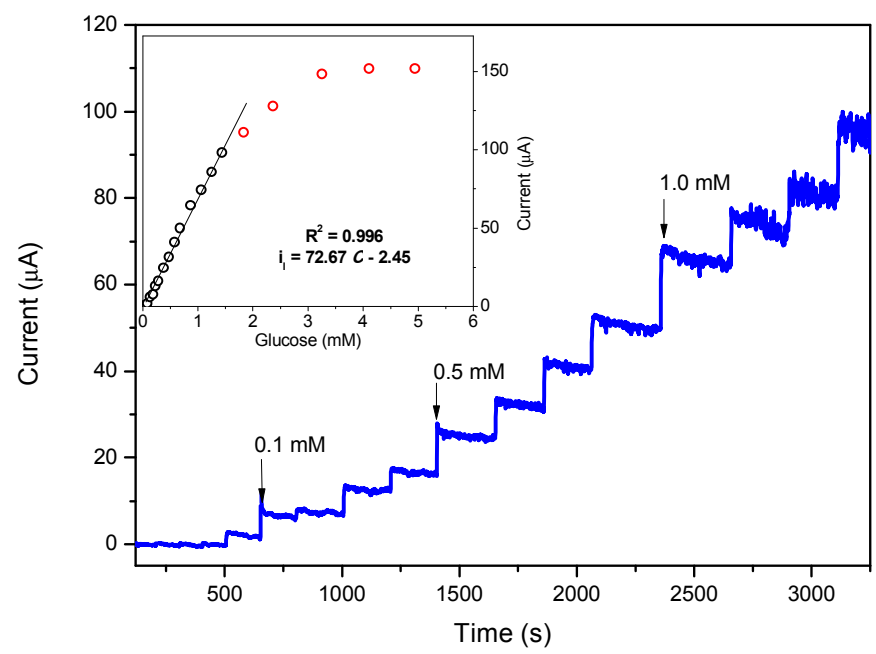

Figure 6. Chronoamperometry of $20 \mu \mathrm{L}$-CS/SPCE in $0.1 \mathrm{M} \mathrm{KOH}$ after successive additions of glucose at an optimal applied potential of $0.6 \mathrm{~V}$; inset shows the corresponding calibration curve.

Table 1 compares the obtained result with those of similar sensors. Despite the lower quantity of nickel used in the formulation of the active material $(1 \mathrm{wt} \%$ of $\mathrm{Ni})$, the performances of the proposed $\mathrm{N}-\mathrm{CS} / \mathrm{SPCE}$ were comparable with other ones. Interestingly, the N-CS/SPCE showed an improved linear range and only slightly lower sensitivity than our previous sensor (PF/Ni30) having a high loading (30\%) of nickel [27].

Table 1. Comparison of glucose performances of the N-CS/SPCE with the recently reported nickel-based non-enzymatic glucose sensors.

\begin{tabular}{|c|c|c|c|c|c|}
\hline Electrode & $\begin{array}{c}\text { Sensitivity } \\
\left(\mu \mathrm{A} \cdot \mathrm{mM}^{-1} \cdot \mathrm{cm}^{-2}\right)\end{array}$ & $\begin{array}{l}\text { Linear Range } \\
\text { (mM) }\end{array}$ & $\begin{array}{l}\text { Detection } \\
\text { Limit }(\mu \mathrm{M})\end{array}$ & $\begin{array}{c}\text { Applied } \\
\text { Voltage (V) }\end{array}$ & Reference \\
\hline $\mathrm{N}-\mathrm{CS}$ & 585 & $0.05-1.5$ & 30 & 0.6 & This work \\
\hline $\mathrm{Ni} / \mathrm{NiO}-\mathrm{rGO}$ & 1997 & - & 1.8 & 0.55 & [6] \\
\hline PF/Ni30 & 670 & $0.05-0.5$ & 8 & 0.6 & [27] \\
\hline Ni nanoparticles/CF & 420.4 & $0.002-2.5$ & 1 & 0.6 & [21] \\
\hline $\mathrm{Ni}(\mathrm{OH})_{2}$ nanosheet & $0.65\left(\mu \mathrm{A} \cdot \mathrm{mM}^{-1}\right)$ & $0.25-39.26$ & 23 & 0.55 & {$[1]$} \\
\hline
\end{tabular}

As silica is not electrochemically active, we believe that its main function is to disperse better nickel nanoparticles inside the carbon matrix. Thus, the good electrochemical activity of the N-CS composite in the electroxidation of glucose to glucolactone can be attributed to an enhanced catalyst-support interaction conferred by the hybrid carbon-silica nanostructure which ensured a better dispersion of nickel particles (Scheme 1).

Selectivity of the sensor was evaluated because, most often, selectivity determined the applicability of the sensor in real media. Usually, some other species, such as sucrose, mannose, fructose, uric acid (UA), dopamine (DA) and ascorbic acid (AC), co-exist with glucose in many real samples. Although, normal physiological levels of abovementioned substances are much lower than glucose, these species can potentially interfere with the electrochemical glucose measurement. Figure 7a shows the amperometric response of N-CS/SPCE based sensor during successive additions of $1 \mathrm{mM}$ glucose, $0.1 \mathrm{mM}$ ascorbic acid, $0.1 \mathrm{mM}$ uric acid, $0.1 \mathrm{mM}$ dopamine, and again $1 \mathrm{mM}$ glucose in $0.1 \mathrm{M} \mathrm{KOH}$ at an applied potential of $0.6 \mathrm{~V}$. 


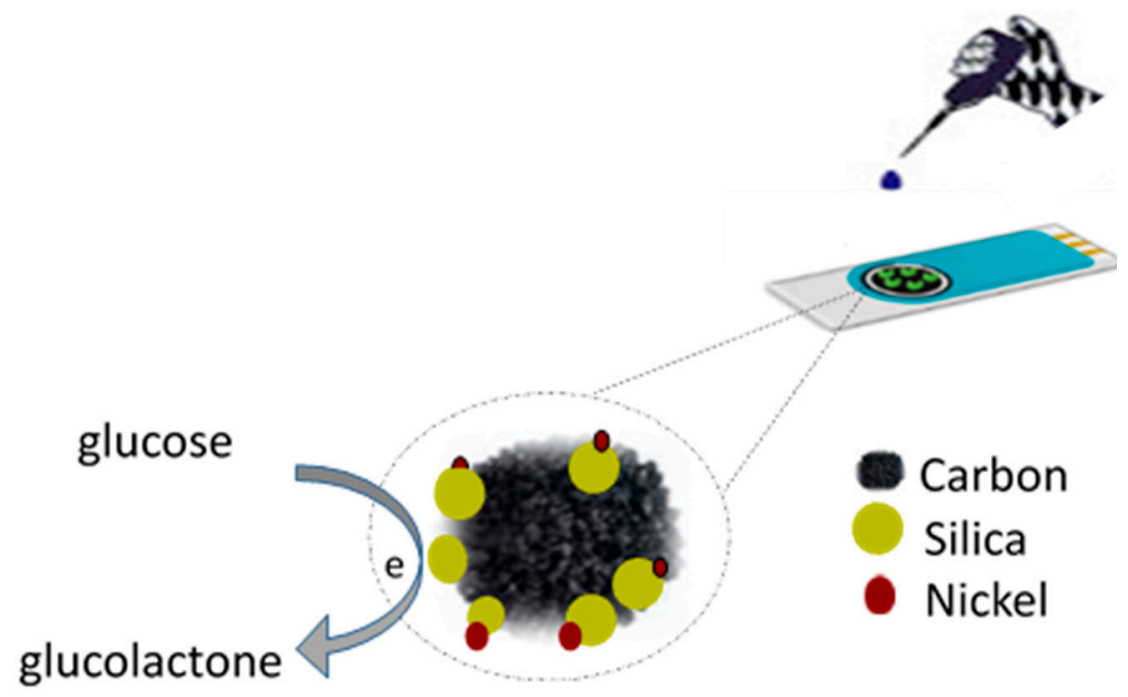

Scheme 1. Schematic representation of the N-CS/SPCE fabrication, the surface of modified working electrode, and the sensing detection mechanism.

Reproducibility of the sensor was also evaluated recording the amperometric response to $1 \mathrm{mM}$ glucose, during ten different measurements (Figure $7 \mathrm{~b}$ ). The results show an excellent reproducibility with a relative standard deviation (RDS) as low as $1.48 \%$. Finally, the stability of the sensor, prepared about six months early, was evaluated using CV, cycling the sensor thirty times in the absence and presence of $0.5 \mathrm{mM}$ glucose in $0.1 \mathrm{M} \mathrm{KOH}$. The main difference has been observed on the shape of the voltammetric curve, however, almost the same oxidation current was observed in the presence of glucose similar to the as-prepared sensor.

This demonstrates that the determination of glucose by the reported sensor was not relevantly affected by the main electroactive molecules, and maintained stable characteristics in the long term; therefore, it may be suitable for glucose monitoring in real physiological samples.

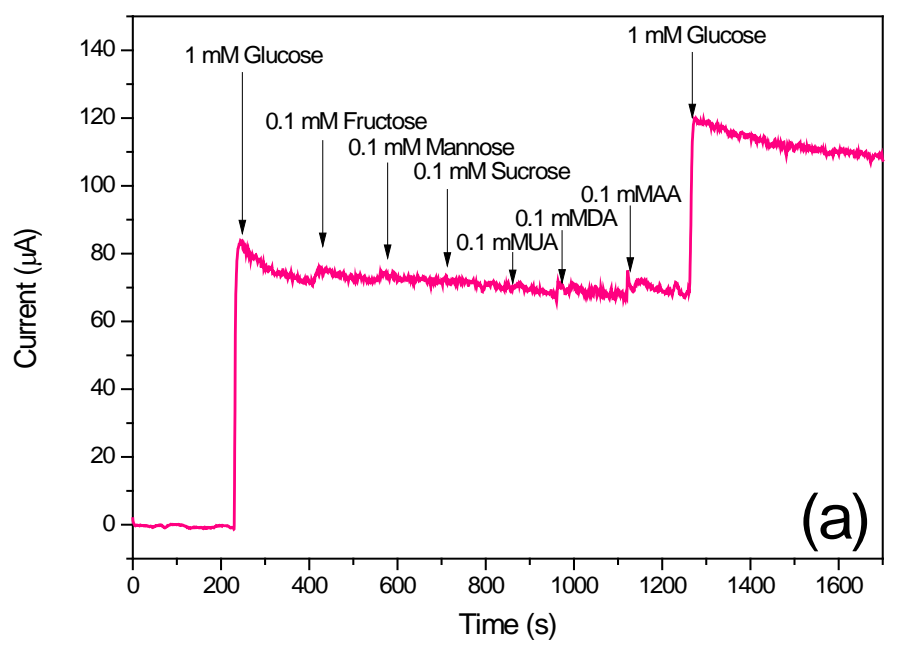

Figure 7. Cont. 

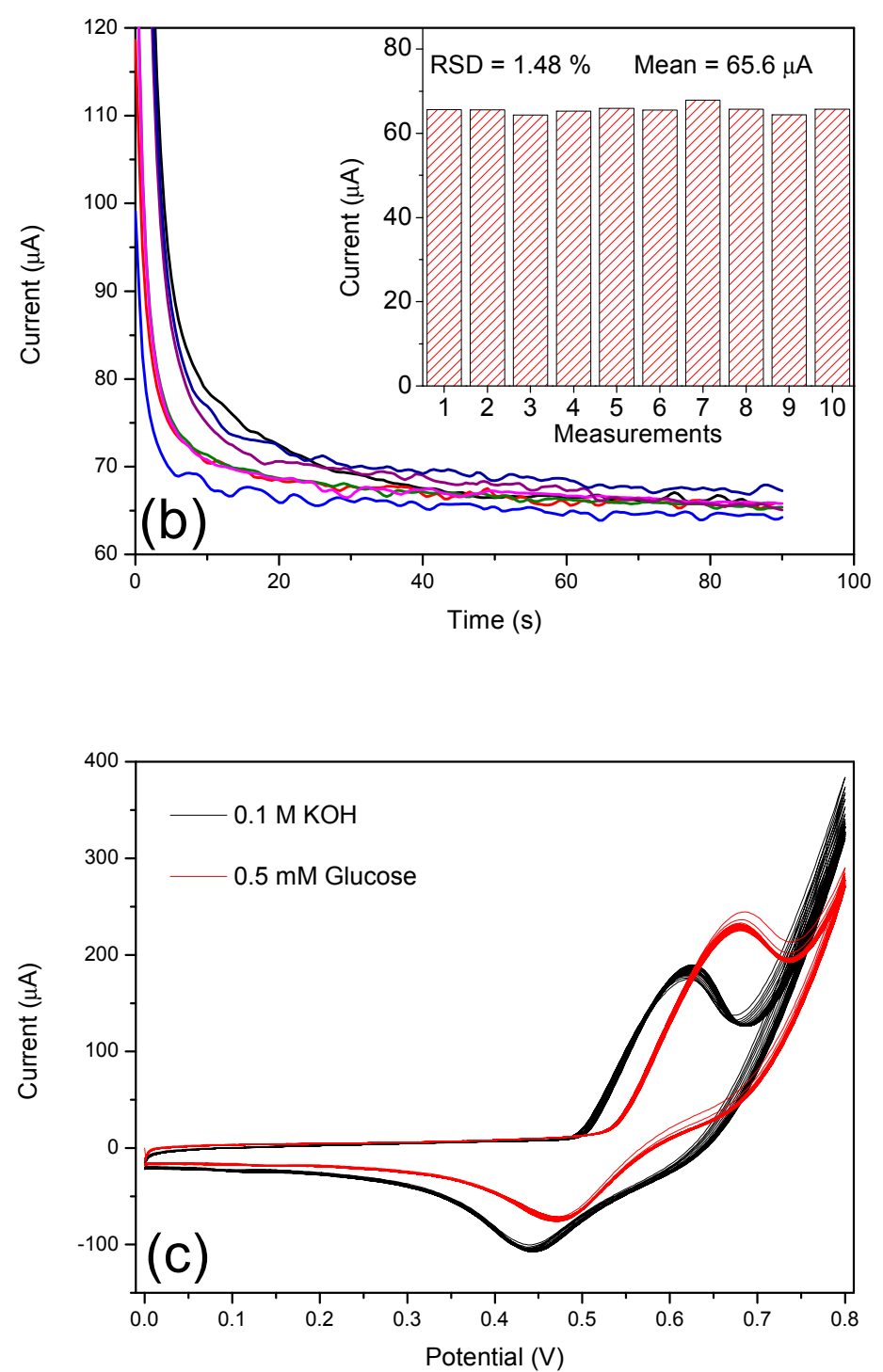

Figure 7. (a) Chronoamperometric response of $20 \mu \mathrm{L} \mathrm{N}-\mathrm{CS} / \mathrm{SPCE}$ in $0.1 \mathrm{M} \mathrm{KOH}$ at $0.6 \mathrm{~V}$ after successive additions of glucose and interfering molecules. (b) Reproducibility of response to $1 \mathrm{mM}$ glucose in $0.1 \mathrm{M} \mathrm{KOH}$. (c) Thirty cycles of CV in the absence and presence of $0.5 \mathrm{mM}$ glucose in $0.1 \mathrm{mM} \mathrm{KOH}$.

\section{Conclusions}

Porous carbon-silica incorporated with nickel (N-CS) was successfully synthesized using a pyrolysis treatment of organic wet gels incorporated with $\mathrm{NiO}$ and $\mathrm{SiO}_{2}$ nanoparticles. XRD results confirmed the formation of a metallic Ni phase and the amorphous nature of carbon-silica matrix. Using SEM analysis, the morphology of the as-prepared N-CS composite showed a uniform porous structure that appeared more rough and porous after the electrochemical activation of the material on the screen-printed carbon electrode.

An electrochemical glucose sensor was prepared by modifying the surface of screen-printed carbon electrode by a simple drop casting method. The activation of the nickel was carried out using cyclic voltammetry in a $0.1 \mathrm{M} \mathrm{KOH}$ solution, cycling the modified electrode in a potential window from 0 to $0.8 \mathrm{~V}$. The evolution of the CV cycle by cycle suggested the formation of an oxy-hydroxide species that involved the entire bulk of nickel present in the composite. Although the quantity of nickel in the composite was as low as $1 \mathrm{wt} \%$, the developed sensor howed good sensing performance towards glucose monitoring with a sensitivity of $585 \mu \mathrm{A} \cdot \mathrm{mM}^{-1} \cdot \mathrm{cm}^{-1}$ in a linear range from 0.05 to $1.5 \mathrm{mM}$, a detection limit lower than $30 \mu \mathrm{M}$, and excellent selectivity. The good electrochemical performance of 
the N-CS composite can be ascribed to a high dispersion of nickel phase in the composite due to an enhanced catalyst-support interaction conferred by the hybrid nanostructure. This study demonstrates a new approach to prepare efficient electrocatalytic materials in which the amount of catalyst is greatly reduced while good sensing performance is still retained.

Author Contributions: Conceptualization, N.Z., S.M., N.B.M., M.H., C.E., L.E.M.; Investigation, N.Z., S.M., N.B.M., M.H., C.E.; Writing-Original Draft Preparation, S.G.L.; Writing-Review \& Editing, G.N.

Conflicts of Interest: The authors declare no conflict of interest.

\section{References}

1. Wang, Z.; Hu, Y.; Yang, W.; Zhou, M.; Hu, X. Facile One-Step Microwave-Assisted Route towards Ni Nanospheres/Reduced Graphene Oxide Hybrids for Non-Enzymatic Glucose Sensing. Sensors 2012, 12, 4860. [CrossRef] [PubMed]

2. Chen, C.; Xie, Q.; Yang, D.; Xiao, H.; Fu, Y.; Tan, Y.; Yao, S. Recent advances in electrochemical glucose biosensors: A review. RSC Adv. 2013, 3, 4473-4491. [CrossRef]

3. Zhang, Y.; Su, L.; Manuzzi, D.; de los Monteros, H.V.E.; Jia, W.; Huo, D.; Hou, C.; Lei, Y. Ultrasensitive and selective non-enzymatic glucose detection using copper nanowires. Biosens. Bioelectron. 2012, 31, 426-432. [CrossRef] [PubMed]

4. Guo, C.X.; Zheng, X.T.; Lu, Z.S.; Lou, X.W.; Li, C.M. Biointerface by Cell Growth on Layered Graphene-Artificial Peroxidase-Protein Nanostructure for In Situ Quantitative Molecular Detection. Adv. Mater. 2010, 22, 5164-5167. [CrossRef] [PubMed]

5. Lei, Y.; Yan, X.; Zhao, J.; Liu, X.; Song, Y.; Luo, N.; Zhang, Y. Improved glucose electrochemical biosensor by appropriate immobilization of nano-ZnO. Colloids Surfaces B Biointerfaces 2011, 82, 168-172. [CrossRef] [PubMed]

6. Zhang, X.; Zhang, Z.; Liao, Q.; Liu, S.; Kang, Z.; Zhang, Y. Nonenzymatic Glucose Sensor Based on In Situ Reduction of Ni/NiO-Graphene Nanocomposite. Sensors 2016, 16, 1791. [CrossRef] [PubMed]

7. Espro, C.; Donato, N.; Galvagno, S.; Aloisio, D.; Leonardi, S.G.; Neri, G. CuO nanowires-based electrodes for glucose sensors. Chem. Eng. 2014, 41. [CrossRef]

8. Gao, X.; Lu, Y.; Liu, M.; He, S.; Chen, W. Sub-nanometer sized Cu6(GSH)3 clusters: One-step synthesis and electrochemical detection of glucose. J. Mater. Chem. C 2015, 3, 4050-4056. [CrossRef]

9. Leonardi, S.G.; Marini, S.; Espro, C.; Bonavita, A.; Galvagno, S.; Neri, G. In-situ grown flower-likenanostructured $\mathrm{CuO}$ on screen printed carbon electrodes for non-enzymatic amperometric sensing of glucose. Microchim. Acta 2017, 184, 2375-2385. [CrossRef]

10. Xu, F.; Sun, Y.; Zhang, Y.; Shi, Y.; Wen, Z.; Li, Z. Graphene-Pt nanocomposite for nonenzymatic detection of hydrogen peroxide with enhanced sensitivity. Electrochem. Commun. 2011, 13, 1131-1134. [CrossRef]

11. Lu, L.-M.; Li, H.-B.; Qu, F.; Zhang, X.-B.; Shen, G.-L.; Yu, R.-Q. In situ synthesis of palladium nanoparticle-graphene nanohybrids and their application in nonenzymatic glucose biosensors. Biosens. Bioelectron. 2011, 26, 3500-3504. [CrossRef] [PubMed]

12. Luo, J.; Jiang, S.; Zhang, H.; Jiang, J.; Liu, X. A novel non-enzymatic glucose sensor based on Cu nanoparticle modified graphene sheets electrode. Anal. Chim. Acta 2012, 709, 47-53. [CrossRef] [PubMed]

13. Zhu, J.; Jiang, J.; Liu, J.; Ding, R.; Li, Y.; Ding, H.; Feng, Y.; Wei, G.; Huang, X. CNT-network modified Ni nanostructured arrays for high performance non-enzymatic glucose sensors. RSC Adv. 2011, 1, 1020-1025. [CrossRef]

14. Mu, Y.; Jia, D.; He, Y.; Miao, Y.; Wu, H.-L. Nano nickel oxide modified non-enzymatic glucose sensors with enhanced sensitivity through an electrochemical process strategy at high potential. Biosens. Bioelectron. 2011, 26, 2948-2952. [CrossRef] [PubMed]

15. Lu, L.-M.; Zhang, L.; Qu, F.-L.; Lu, H.-X.; Zhang, X.-B.; Wu, Z.-S.; Huan, S.-Y.; Wang, Q.-A.; Shen, G.-L.; $\mathrm{Yu}, \mathrm{R} . \mathrm{Q}$. A nano-Ni based ultrasensitive nonenzymatic electrochemical sensor for glucose: Enhancing sensitivity through a nanowire array strategy. Biosens. Bioelectron. 2009, 25, 218-223. [CrossRef] [PubMed]

16. Ci, S.; Huang, T.; Wen, Z.; Cui, S.; Mao, S.; Steeber, D.A.; Chen, J. Nickel oxide hollow microsphere for non-enzyme glucose detection. Biosens. Bioelectron. 2014, 54, 251-257. [CrossRef] [PubMed] 
17. Zhang, Y.; Xu, F.; Sun, Y.; Shi, Y.; Wen, Z.; Li, Z. Assembly of Ni(OH)2 nanoplates on reduced graphene oxide: A two dimensional nanocomposite for enzyme-free glucose sensing. J. Mater. Chem. 2011, 21, 16949-16954. [CrossRef]

18. Wang, G.; He, X.; Wang, L.; Gu, A.; Huang, Y.; Fang, B.; Geng, B.; Zhang, X. Non-Enzymatic Electrochemical Sensing of Glucose. Microchim. Acta 2013, 180, 161-186. [CrossRef]

19. Guo, Q.; Liu, D.; Zhang, X.; Li, L.; Hou, H.; Niwa, O.; You, T. Pd-Ni Alloy Nanoparticle/Carbon Nanofiber Composites: Preparation, Structure, and Superior Electrocatalytic Properties for Sugar Analysis. Anal. Chem. 2014, 86, 5898-5905. [CrossRef] [PubMed]

20. Yu, S.; Peng, X.; Cao, G.; Zhou, M.; Qiao, L.; Yao, J.; He, H. Ni nanoparticles decorated titania nanotube arrays as efficient nonenzymatic glucose sensor. Electrochim. Acta 2012, 76, 512-517. [CrossRef]

21. Liu, Y.; Teng, H.; Hou, H.; You, T. Nonenzymatic glucose sensor based on renewable electrospun Ni nanoparticle-loaded carbon nanofiber paste electrode. Biosens. Bioelectron. 2009, 24, 3329-3334. [CrossRef] [PubMed]

22. Yang, J.; Yu, J.-H.; Rudi Strickler, J.; Chang, W.-J.; Gunasekaran, S. Nickel nanoparticle-chitosan-reduced graphene oxide-modified screen-printed electrodes for enzyme-free glucose sensing in portable microfluidic devices. Biosens. Bioelectron. 2013, 47, 530-538. [CrossRef] [PubMed]

23. Wu, X.; Li, F.; Zhao, C.; Qian, X. One-step construction of hierarchical $\mathrm{Ni}(\mathrm{OH})_{2} / \mathrm{RGO} / \mathrm{Cu}_{2} \mathrm{O}$ on $\mathrm{Cu}$ foil for ultra- sensitive non-enzymatic glucose and hydrogen peroxide detection. Sens. Actuators B 2018, 274, 163-171. [CrossRef]

24. Inagaki, M.; Konno, H.; Tanaike, O. Carbon materials for electrochemical capacitors. J. Power Sources 2010, 195, 7880-7903. [CrossRef]

25. Zhai, Y.; Dou, Y.; Zhao, D.; Fulvio, P.F.; Mayes, R.T.; Dai, S. Carbon materials for chemical capacitive energy storage. Adv. Mater. 2011, 23, 4828-4850. [CrossRef] [PubMed]

26. Zhang, W.; Zhu, S.; Luque, R.; Han, S.; Hu, L.; Xu, G. Recent development of carbon electrode materials and their bioanalytical and environmental applications. Chem. Soc. Rev. 2016, 45, 715-752. [CrossRef] [PubMed]

27. Marini, S.; Ben Mansour, N.; Hjiri, M.; Dhahri, R.; El Mir, L.; Espro, C.; Bonavita, A.; Galvagno, S.; Neri, G.; Leonardi, S.G. Non-enzymatic Glucose Sensor Based on Nickel/Carbon Composite. Electroanalysis 2018, 30, 727-733. [CrossRef]

28. Ren, J.; Hao, P.; Sun, W.; Shi, R.; Liu, S. Ordered mesoporous silica-carbon-supported copper catalyst as an efficient and stable catalyst for catalytic oxidative carbonylation. Chem. Eng. J. 2017, 328, 673-682. [CrossRef]

29. Wan, Y.; Wang, H.; Zhao, Q.; Klingstedt, M.; Terasaki, O.; Zhao, D. Ordered Mesoporous Pd/Silica-Carbon as a Highly Active Heterogeneous Catalyst for Coupling Reaction of Chlorobenzene in Aqueous Media. J. Am. Chem. Soc. 2009, 131, 4541-4550. [CrossRef] [PubMed]

30. Ru, Y.; Evans, D.G.; Zhu, H.; Yang, W. Facile fabrication of yolk-shell structured porous Si-C microspheres as effective anode materials for Li-ion batteries. RSC Adv. 2014, 4, 71-75. [CrossRef]

31. Pissinis, D.E.; Sereno, L.n.E.; Marioli, J.M. Utilization of Special Potential Scan Programs for Cyclic Voltammetric Development of Different Nickel Oxide-Hydroxide Species on Ni Based Electrodes. Open J. Phys. Chem. 2012, 2, 11. [CrossRef]

32. Vuković, M. Voltammetry and anodic stability of a hydrous oxide film on a nickel electrode in alkaline solution. J. Appl. Electrochem. 1994, 24, 878-882. [CrossRef]

33. Seghiouer, A.; Chevalet, J.; Barhoun, A.; Lantelme, F. Electrochemical oxidation of nickel in alkaline solutions: A voltammetric study and modelling. J. Electroanal. Chem. 1998, 442, 113-123. [CrossRef]

34. Medway, S.L.; Lucas, C.A.; Kowal, A.; Nichols, R.J.; Johnson, D. In situ studies of the oxidation of nickel electrodes in alkaline solution. J. Electroanal. Chem. 2006, 587, 172-181. [CrossRef]

35. Marioli, J.M.; Sereno, L.E. Electrochemical Detection of Underivatized Amino Acids with a Ni-Cr Alloy Electrode. J. Liquid Chromatogr. Related Technol. 1996, 19, 2505-2515. [CrossRef]

36. Bode, H.; Dehmelt, K.; Witte, J. Zur kenntnis der nickelhydroxidelektrode-I. Über das nickel (II)-hydroxidhydrat. Electrochim. Acta 1966, 11. [CrossRef]

37. Zhang, Y.; Xiao, X.; Sun, Y.; Shi, Y.; Dai, H.; Ni, P.; Hu, J.; Li, Z.; Song, Y.; Wang, L. Electrochemical Deposition of Nickel Nanoparticles on Reduced Graphene Oxide Film for Nonenzymatic Glucose Sensing. Electroanalysis 2013, 25, 959-966. [CrossRef]

38. Toghill, K.E.; Compton, R.G. Electrochemical non-enzymatic glucose sensors: A perspective and an evaluation. Int. J. Electrochem. Sci 2010, 5, 1246-1301. 
39. Al-Omair, M.A.; Touny, A.H.; Al-Odail, F.A.; Saleh, M.M. Electrocatalytic Oxidation of Glucose at Nickel Phosphate Nano/Micro Particles Modified Electrode. Electrocatalysis 2017, 8, 340-350. [CrossRef]

40. Wang, L.; Lu, X.; Wen, C.; Xie, Y.; Miao, L.; Chen, S.; Li, H.; Li, P.; Song, Y. One-step synthesis of Pt-NiO nanoplate array/reduced graphene oxide nanocomposites for nonenzymatic glucose sensing. J. Mater. Chem. A 2015, 3, 608-616. [CrossRef] 